\title{
Factors that Differentiate Winning and Losing in Men's University Basketball
}

\author{
Kenneth Marius R. Raval', Jeffrey C. Pagaduan² \\ Affiliations: 'University of the Philippines, College of Human Kinetics, Department of Physical Education, Quezon City, Philippines, ${ }^{2}$ University of
} Tasmania, College of Medicine, School of Health Sciences, Hobart, Australia

Correspondence: K.M.R. Raval, University of the Philippines, Department of Physical Education, Corner Magsaysay and E. Jacinto Streets, Diliman, 1101, Quezon City, Philippines. E-mail: krraval1@up.edu.ph

\begin{abstract}
The objective of this study is to analyse the game-related statistics that differentiate winning and losing teams, according to the finale game scores in a men's university basketball league. Samples were gathered from the archival data of the 2019-2020 regular season of the league. Sixteen game-related statistics were analysed: two- and three-point field-goals (both successful and unsuccessful), free-throws (both successful and unsuccessful), defensive and offensive rebounds, assists, steals, turnover, blocks, second-chance points, fast break points, fouls committed and received. The data were clustered into different game types based on the final outcome point differences: all games, balanced games ( 11 points and below) and unbalanced games ( 12 points and above). Discriminant function analysis was conducted to identify the performance indicators that classify winning and losing games. The results revealed that winning and losing in balanced games were discriminated by successful two-point field goals, unsuccessful two-point field goals, unsuccessful three-point field goals, successful free-throws, assists, steals, blocks, second-chance points, fast-break points, fouls committed, and fouls received. For unbalanced games, winning and losing were distinguished by successful two-point field goals, successful three-point field goals, successful free-throws, unsuccessful free-throws, defensive rebounds, blocks, fast-break points, and fouls received. In conclusion, offensive and defensive indices are critical to winning and losing in university-level basketball.
\end{abstract}

Keywords: sports performance, game-related statistics, notational analysis, males

@MJSSMontenegro

WINNING AND LOSING IN MEN'S UNIVERSITY BASKETBALL

http://mjssm.me/?sekcija=article\&artid=217

Cite this article: Raval, K.M.R., \& Pagaduan, J.C. (2021). Factors that Differentiate Winning and Losing in Men's University Basketball. Montenegrin Journal of Sports Science and Medicine, 10 (2), 13-17. doi: 10.26773/ mjssm.210902

\section{Introduction}

Notational analysis is the process of recording, treatment, and diagnostics of events taking place in a competition (Drust, 2010). In basketball, notational analysis plays an essential role in formulating strategies and optimizing training load (Sampaio et al., 2004; Lorenzo et al., 2010; Sampaio et al., 2015).
Also, basketball-related statistics help improve the efficiency of players during the season (Sampaio et al., 2015) and predict final team rankings (Ziv et al., 2010).

Indeed, basketball-related statistics provide useful information in winning and losing games. Ibáñez et al. (2008) demonstrated that field goal attempts and defensive rebounds 
contribute to winning a game in men's basketball. Similarly, Gómez et al. (2008) found that defensive rebounds determined success in balanced and unbalanced games in men's basketball. In another study, Ibáñez et al. (2008) found that two-point field goal attempts and defensive rebounds differentiated winning and losing in balanced games while only successful two-point field goals significantly affected the result in unbalanced games. Csátaljay et al. (2009) revealed that threepoint performance, free throws, and defensive rebounding were decisive in winning and losing.

Recent trends in basketball notational analysis include fast breaks and second-chance points. Evangelos et al. (2005) suggested that the fast break is an important factor in winning games. It presents a higher scoring opportunity by delaying defensive set-up. In contrast, second-chance points reflect success in scoring after an offensive rebound. Conte and Lukonaitiene (2018) noted that winning teams have a higher number of second-chance points compared to the losing team during unbalanced games. Both fast break and second-chance points increase field goal attempts, leading to higher chances of scoring (Sampaio \& Janeira, 2003).

In the university basketball settings in the Philippines, there seems to be a paucity in the literature that distinguish factors that affect the outcome of a basketball game. Such information will allow better interpretation of the game and logically increase the applicability to improve training plans (Sampaio \& Janeira, 2003; Gómez et al., 2008). Furthermore, basketball game-related statistics can aid in the long-term development of university basketball programmes. Therefore, this study aims to analyse the game-related statistics that differentiate winning and losing teams in a university basketball league in the Philippines.

\section{Methods}

This study covered fifty-six regular-season games from the 2019-2020 university basketball league in the Philippines. The following game-related statistics were used: two-point field goals (successful and unsuccessful), three-point field goals (successful and unsuccessful), free throws (successful and unsuccessful), defensive rebounds, offensive rebounds, assists, steals, turnovers, second-chance points, fast-break points, fouls (committed and received), blocks, recovered ball possessions, and ball possessions.

The collected game statistics were normalized to ball possessions (BP) multiplied by 100 . Ball possession was calculated as $\mathrm{BP}=($ field-goals attempted $)-($ offensive rebounds $)+($ turn overs $)-0.4 \times$ (free-throws attempted) (Oliver, 2004).

To control for the effects of the situational variables, the game types were obtained using k-cluster analysis, allowing a cut-off value of point differences in the outcome of a given game. The cluster analysis classified $67.0 \%(n=75)$ of the games with final score differences of 12 points and above (unbalanced games), while $33.0 \%(n=37)$ of the games have score differences of 11 points and below (balanced games).

An independent samples T-test was conducted to differentiate game-related statistics between winning and losing teams. A discriminant function analysis was conducted to identify the separators in winning (Group 1) and losing teams (Group 2). A structural coefficient (SC) of above 0.30 was used as the criteria for differentiating variables in winning and losing (Gómez et al., 2008). The discriminant score (D) was derived from the unstandardized discriminant function coef- ficients $(\beta)$ to predict the game outcome computed as $D=\beta 0$ $+\beta 1 \times \mathrm{V} 1+\ldots \beta 15 \times \mathrm{V} 15$, where $\beta 0$ is the constant value, $\beta 1-\beta 15$ are the unstandardized coefficients for each variable, V1-V15 are the values of game-related statistics (Gómez et al., 2014). The group prediction was made from the cutting scores of the centroids, calculated as: cutting score $=$ (mean centroid $1+$ mean centroid 2) / 2. Values with $\mathrm{D}>$ cutting point will be in Group 1. D values < cutting point will be assigned to Group 2. Statistical analyses were carried out using the commercial statistical package (IBM SPSS ver 25, Armonk, NY) with alpha set at 0.05 level.

\section{Results}

All Games

The result showed that both successful and unsuccessful two-point field goals were significantly different in winning and losing games at $\mathrm{t}(110)=3.13, \mathrm{p}=0.00$ and $\mathrm{t}(110)=-2.70$, $\mathrm{p}=0.00$, respectively. Successful three-point field goals were also statistically significant at $\mathrm{t}(110)=3.83, \mathrm{p}=0.00$. Another parameter that showed significant difference were defensive rebounds at $\mathrm{t}(110)=3.91, \mathrm{p}=0.00$. Assists were also statistically significant between winning and losing games at $\mathrm{t}(110)=$ $6.56, \mathrm{p}=0.00$. Blocks were statistically different between winning and losing teams at $\mathrm{t}(110)=4.80, \mathrm{p}=0.00$. There was also a significant difference between winning and losing teams for second chance points at $\mathrm{t}(110)=4.16, \mathrm{p}=0.00$.

\section{Balanced Games}

There was a significant difference in successful three-point field-goals between winning and losing games, $t(35)=2.25$, $\mathrm{p}=0.03$. Assists were significantly different in winning and losing games at $\mathrm{t}(35)=3.48, \mathrm{p}=0.00$. A significant difference in blocks also existed between winning and losing games, $\mathrm{t}(35)$ $=3.30, \mathrm{p}=0.00$.

\section{Unbalanced Games}

There was a significant difference in successful two-point field goals between and losing games, $\mathrm{t}(73)=3.92, \mathrm{p}=0.00$ and in unsuccessful two-point field goals, $\mathrm{t}(73)=-2.99, \mathrm{p}=$ 0.00 . Successful three-point field goals showed a significant difference at $\mathrm{t}(73)=3.11, \mathrm{p}=0.00$. A significant difference is also found in defensive rebound at $\mathrm{t}(73)=2.940, \mathrm{p}=0.004$. A significant difference in assists also existed between winning and losing games at $t(73)=5.09, p=0.00$. Blocks showed significant difference between winning and losing games at $\mathrm{t}(73)$ $=2.88, \mathrm{p}=0.00$. Lastly, fast break points were also statistically significant in winning and losing games, $\mathrm{t}(73)=3.61, \mathrm{p}=0.00$.

\section{Discriminant Analysis for All Games}

The discriminant analysis cross-validation percentage in winning and losing in all games was $88.4 \%$. The most powerful discriminators in winning and losing in men's university basketball were the successful two-point field-goals $(\mathrm{SC}=0.32$ ), successful three-point field goals (SC $=0.57$ ), unsuccessful three-point field-goals, successful free-throws $(\mathrm{SC}=-0.47)$, defensive rebounds ( $S C=0.62$ ), assists ( $S C=0.31$ ), steals (SC $=0.33$ ), and blocks $(\mathrm{SC}=0.43)$. The cutting score for all games is 0.00 , and $\mathrm{D}=-6.80+0.05 \times$ successful two-point field goals $x-0.02 \times$ unsuccessful two-point field goals $+0.13 \times$ successful three-point field goals $-0.04 \times$ unsuccessful three-point field goals - $0.04 \times$ successful free-throws $-0.04 \times$ unsuccessful free-throws $+0.07 \times$ defensive rebounds $+0.02 \times$ offensive 
Table 1. Differences in basketball-related statistics

\begin{tabular}{|c|c|c|c|c|c|c|}
\hline & \multicolumn{2}{|c|}{ All Games $(n=112)$} & \multicolumn{2}{|c|}{ Balanced $(n=37)$} & \multicolumn{2}{|c|}{ Unbalanced $(\mathrm{n}=75)$} \\
\hline & Winners & Losers & Winners & Losers & Winners & Losers \\
\hline Successful 2-point field goals*\# & $32.4 \pm 6.60$ & $28.5 \pm 6.40$ & $33.4 \pm 7.94$ & $35.0 \pm 4.82$ & $31.5 \pm 5.36$ & $26.5 \pm 5.48$ \\
\hline Unsuccessful 2-point field goalsł & $36.9 \pm 9.68$ & $41.5 \pm 8.46$ & $40.2 \pm 9.95$ & $46.0 \pm 8.25$ & $34.2 \pm 8.74$ & $40.1 \pm 8.10$ \\
\hline Successful 3-point field goals*\#\# & $13.2 \pm 5.01$ & $9.90 \pm 3.91$ & $13.4 \pm 6.56$ & $9.03 \pm 3.32$ & $12.9 \pm 3.54$ & $10.1 \pm 4.07$ \\
\hline Unsuccessful 3-point field goals & $29.4 \pm 9.33$ & $28.9 \pm 8.74$ & $33.9 \pm 9.59$ & $34.8 \pm 8.97$ & $25.9 \pm 7.57$ & $27.2 \pm 7.95$ \\
\hline Successful free-throws & $16.6 \pm 12.2$ & $16.1 \pm 9.56$ & $28.8 \pm 11.6$ & $27.3 \pm 8.36$ & $11.5 \pm 5.76$ & $8.09 \pm 4.23$ \\
\hline Unsuccessful free-throws & $10.5 \pm 6.06$ & $9.30 \pm 5.15$ & $13.4 \pm 6.83$ & $13.1 \pm 4.86$ & $8.09 \pm 4.23$ & $8.12 \pm 4.69$ \\
\hline Defensive rebounds* ${ }^{*}$ & $50.7 \pm 9.18$ & $44.5 \pm 8.81$ & $55.1 \pm 8.63$ & $50.6 \pm 9.69$ & $47.9 \pm 8.45$ & $42.4 \pm 7.6$ \\
\hline Offensive rebounds & $24.7 \pm 8.18$ & $23.6 \pm 8.48$ & $31.0 \pm 7.00$ & $31.5 \pm 9.40$ & $20.0 \pm 5.30$ & $21.2 \pm 6.29$ \\
\hline Assists*\#\# & $27.5 \pm 6.87$ & $18.9 \pm 5.20$ & $28.4 \pm 7.78$ & $19.8 \pm 5.83$ & $25.1 \pm 5.82$ & $18.7 \pm 5.04$ \\
\hline Steals & $8.20 \pm 4.11$ & $7.80 \pm 3.87$ & $9.48 \pm 5.27$ & $8.51 \pm 4.17$ & $8.23 \pm 2.93$ & $7.54 \pm 3.80$ \\
\hline Turnovers & $24.0 \pm 8.04$ & $24.9 \pm 6.38$ & $26.8 \pm 9.61$ & $22.8 \pm 7.15$ & $23.1 \pm 6.34$ & $25.5 \pm 6.07$ \\
\hline Blocks*\#キ & $7.10 \pm 3.90$ & $4.45 \pm 2.66$ & $8.99 \pm 3.62$ & $5.26 \pm 2.48$ & $6.36 \pm 3.76$ & $4.21 \pm 2.69$ \\
\hline $2^{\text {nd }}$ chance points* & $26.4 \pm 11.5$ & $20.1 \pm 8.39$ & $32.2 \pm 11.5$ & $27.5 \pm 7.65$ & $19.9 \pm 8.32$ & $17.8 \pm 7.29$ \\
\hline Fast break points $\ddagger$ & $18.2 \pm 6.87$ & $13.1 \pm 6.37$ & $20.2 \pm 6.71$ & $17.5 \pm 7.27$ & $16.8 \pm 6.70$ & $11.7 \pm 5.47$ \\
\hline Fouls committed & $25.5 \pm 7.20$ & $28.4 \pm 7.26$ & $28.9 \pm 8.75$ & $31.1 \pm 8.00$ & $25.6 \pm 5.48$ & $27.5 \pm 6.90$ \\
\hline Fouls received & $28.2 \pm 10.79$ & $27.0 \pm 8.92$ & $38.2 \pm 10.0$ & $36.7 \pm 6.36$ & $23.6 \pm 6.12$ & $24.1 \pm 7.42$ \\
\hline Recovered Ball Possession & $15.7 \pm 5.72$ & $12.2 \pm 4.75$ & $15.5 \pm 5.06$ & $13.2 \pm 4.95$ & $18.0 \pm 6.26$ & $10.9 \pm 4.23$ \\
\hline Ball Possession & $65.6 \pm 7.73$ & $66.3 \pm 7.12$ & $64.3 \pm 8.55$ & $67.3 \pm 7.27$ & $65.5 \pm 6.67$ & $65.0 \pm 6.86$ \\
\hline
\end{tabular}

Note: *significant in all games at $\mathrm{p}<0.05$; \#significant in balanced games at $\mathrm{p}<0.05$; 捛nificant in unbalanced games at $\mathrm{p}<0.05$.

rebounds $+0.05 \times$ assists $+0.08 \times$ steals $+0.13 \times$ blocks $+0.00 \times$ second-chance points $+0.04 \times$ fast-break points $-0.02 \times$ fouls committed $+0.01 \times$ fouls received.

\section{Discriminant Analysis for Balanced Games}

There was a $86.5 \%$ cross-validation percentage in winning and losing in balanced games. Powerful discriminators in win-

Table 2. Discriminant analysis structure coefficients for game-related statistics of winning and losing games

\begin{tabular}{|c|c|c|c|}
\hline Game-related statistics & All Games & Balanced & Unbalanced \\
\hline Successful 2-point field goals abc & 0.32 & -0.50 & 0.63 \\
\hline Unsuccessful 2-point field goals ${ }^{b}$ & -0.17 & -0.30 & -0.09 \\
\hline Successful 3-point field goals ${ }^{\text {ac }}$ & 0.57 & 0.05 & 0.59 \\
\hline Unsuccessful 3-point field goals ${ }^{\text {ab }}$ & -0.38 & -0.52 & -0.27 \\
\hline Successful free-throws ${ }^{\text {abc }}$ & -0.47 & 0.38 & -0.67 \\
\hline Unsuccessful free-throws ${ }^{c}$ & -0.20 & 0.19 & -0.42 \\
\hline Defensive rebounds ${ }^{\mathrm{ac}}$ & 0.62 & 0.18 & 0.61 \\
\hline Offensive rebounds & 0.15 & -0.14 & 0.06 \\
\hline Assistsab & 0.31 & 0.91 & 0.21 \\
\hline Stealsab & 0.33 & 0.65 & 0.24 \\
\hline Blocksabc & 0.43 & 0.84 & 0.36 \\
\hline $2^{\text {nd }}$ chance points $^{b}$ & 0.03 & 0.64 & -0.06 \\
\hline Fast break points ${ }^{\mathrm{bc}}$ & 0.24 & -0.30 & 0.31 \\
\hline Fouls committed ${ }^{b}$ & -0.11 & 0.30 & -0.17 \\
\hline Fouls received ${ }^{b c}$ & 0.11 & -1.11 & 0.45 \\
\hline Eigenvalue & 1.14 & 1.66 & 1.50 \\
\hline Wilks Lambda & 0.47 & 0.38 & 0.40 \\
\hline Canonical Correlation & 0.73 & 0.79 & 0.77 \\
\hline Chi-square & 77.9 & 26.9 & 60.0 \\
\hline DF & 15 & 15 & 15 \\
\hline$P$ & 0.00 & 0.03 & 0.00 \\
\hline Reclassification \% & 88.4 & 86.5 & 93.3 \\
\hline
\end{tabular}

Note: ${ }^{a}$ Structure coefficient discriminant values $\geq 0.30$ in all games; ${ }^{b}$ Structure coefficient discriminant values $\geq 0.30$ in balanced games; 'Structure coefficient discriminant values $\geq 0.30$ in unbalanced games. 
ning and losing in balance games were successful two-point field goals $(\mathrm{SC}=-0.50)$, unsuccessful two-point field goals $(\mathrm{SC}=-0.30)$, unsuccessful three-point field goals $(\mathrm{SC}=-0.52)$, successful free-throws $(\mathrm{SC}=0.38)$, assists $(\mathrm{SC}=0.91)$, steals $(\mathrm{SC}=0.65)$, blocks $(\mathrm{SC}=0.84)$, second-chance points $(\mathrm{SC}=$ $0.64)$, fast-break points $(\mathrm{SC}=-0.30)$, fouls committed $(\mathrm{SC}=$ 0.30 ), and fouls received ( $\mathrm{SC}=-1.11$ ). The cutting score for balanced games is -0.39 , and $\mathrm{D}=-0.21-0.07 \times$ successful twopoint field goals $\times-0.03 \times$ unsuccessful two-point field goals + $0.01 \times$ successful three-point field goals $-0.06 \times$ unsuccessful three-point field goals $+0.04 \times$ successful free-throws +0.03 $\times$ unsuccessful free-throws $+0.02 \times$ defensive rebounds -0.02 $\times$ offensive rebounds $+0.13 \times$ assists $+0.13 \times$ steals +0.26 $\times$ blocks $+0.06 \times$ second-chance points $-0.04 \times$ fast-break points $+0.04 \times$ fouls committed $-0.12 \times$ fouls received.

\section{Discriminant Analysis for Unbalanced Games}

For unbalanced games, there was a $93.3 \%$ cross-validation percentage in winning and losing games. Powerful discriminators include successful two-point field goals $(S C=0.63)$, successful three-point field goals ( $\mathrm{SC}=0.59)$, successful free-throws $(S C=-0.67)$, unsuccessful free-throws $(S C=-0.42)$, defensive rebounds ( $\mathrm{SC}=0.61$ ), blocks ( $\mathrm{SC}=0.36$ ), fast-break points ( $\mathrm{SC}$ $=0.31)$ and fouls received $(S C=0.45)$. The cutting score for balanced games is 0.179 , and $\mathrm{D}=-8.72+0.12 \times$ successful twopoint field goals $\times-0.10 \times$ unsuccessful two-point field goals + $0.15 \times$ successful three-point field goals $-0.04 \times$ unsuccessful three-point field goals $-0.10 \times$ successful free-throws $-0.09 \times$ unsuccessful free-throws $+0.08 \times$ defensive rebounds $-0.01 \times$ offensive rebounds $+0.04 \times$ assists $+0.07 \times$ steals $+0.11 \times$ blocks $-0.01 \times$ second chance points $+0.05 \times$ fast-break points $-0.03 \times$ fouls committed $+0.07 \times$ fouls received.

\section{Discussion}

The purpose of this study was to identify the factors that differentiate winning and losing teams in a university basketball league in the Philippines. In the present study, successful two-point field goals, successful free throws and blocks were the most powerful variables in differentiating between winning and losing teams in all three analyses: all games, balanced games, and unbalanced games. Field goal shooting is the most fundamental skill of the game as it shows the offensive quality of the winning team (Sampaio et al., 2006). Additionally, successful field-goal shooting reflects an efficient offensive system that contributes to the higher possibility of winning the game. Successful free throws are also a crucial performance indicator as they contribute to achieving a higher number of scored points (Csátaljay et al., 2009). The development of fundamental sequences in field-goal and free-throw shooting, with progression to game-like conditions lead to shooting efficiency, thereby providing a better opportunity for positive game outcome. Blocks, in contrast, prevent the opponent from scoring (Ibáñez et al., 2008). Blocking entails timing and anticipation that add to a good team defensive system.

In balanced games, winning and losing games were differentiated by successful two-point field goals, unsuccessful twopoint field goals, unsuccessful tree-point field goals, successful free-throws, assists, second-chance points, fast-break points, steals, blocks, and fouls committed, Winning teams demonstrated better field goal efficiency through higher successful two-point field goals and free throws while exhibiting lower unsuccessful two-point and three-point field goals. Winning teams also posted more assists made than losing teams did in balanced games. Assists indicate teamwork and better selection of moment to pass the ball (Sampaio et al., 2004; Garcia et al., 2013). The selection of field goal opportunities results in higher field goal percentages (Sampaio \& Janeira, 2003). Winning teams executed more fast-break occurrences. This finding coincides with the results presented by Conte et al. (2017), which showed that more fast breaks increased winning percentage in both elite and sub-elite basketball teams. The fast break is an important element in the offensive basketball system because it reduces the transition time from defence to offence (Krause et al., 2008). Some coaches prefer fast breaks as the first option in any offensive attack due to the advantages it creates for the team (Wootten \& Wootten, 2012). Taking advantage of the open court with fast breaks shifts the momentum to the offensive team with minimal or no defensive set-up in such situations.

Winning teams also presented more second-chance points than losing teams did in balanced games. More scoring opportunities are made available with second-chance points (Ibáñez et al., 2008). The second-chance points reflect the persistence and creativity to score from spontaneous conditions. In this study, winning teams received more fouls from the opponents. This situation increases scoring momentum by allowing more time for offensive set-up or scoring unguarded via free throws. On parameters related to defence, winning teams displayed more steals and blocks.

Additionally, winning teams committed fewer fouls. Steals, blocks, and fewer fouls represent defensive effectiveness, reducing the scoring chances of opponents (Ibáñez et al., 2008). Thus, winning teams in balanced games created more opportunities for scoring and were successful in executing the offensive moments. The offensive advantage in winning games was accompanied by greater defensive abilities in steals, blocks, and lower fouls.

In unbalanced games, winning and losing teams were differentiated by successful two-point field goals, successful three-point field goals, successful free-throws, unsuccessful free-throws, fast breaks, fouls received, defensive rebounds, and blocks. In this study, winning teams demonstrated better offensive execution from successful two-point field goals, successful three-point field goals, successful free-throws, and unsuccessful free-throws. Higher two-point field goals in winning teams signify better shot selection, leading to an increased shooting percentage (Trninić et al., 2002).

Furthermore, higher success from the three-point area reflects an additional offensive threat to the opponents. The outcomes in two-point and three-point field goal success in winning games in this study decrease the defensive ability of the opposing team by creating a large area for defensive coverage. Successful free throws and unsuccessful free-throws also differentiated winning and losing teams in unbalanced games. Winning teams converted more free throws with minimal failure. The free throw allows an offensive player to shoot in a stable position without a defender (Pakosz \& Konieczny, 2016). Winning and losing during unbalanced games was also differentiated by fast breaks. Winning teams displayed more fast-break points than losing teams did. This situation exhibits the ability of the winning team to score quickly from defensive to offensive transition (Trninić et al., 2002). Another variable that discriminated winning and losing is the total fouls received. Winning teams received fewer fouls than the losing teams did, which translates to fewer interruptions in the of- 
fensive rhythm of winning teams. In regard to defensive skills, winning teams in unbalanced situations posted more defensive rebounds, blocks, and steals than losing teams did. Defensive rebounds indicate aggressive defence, which disrupts offensive play (Sampaio \& Janeira, 2003; Gomez et al., 2008). Blocks and steals stop a team from creating moments for scoring (Trninić et al., 2000). Thus, winning in unbalanced games is discriminated by offensive competence across scoring areas (free throws, two-point field goals and three-point field goals).

Limitations of the current study are acknowledged. First, a generalization of results should be avoided as the findings are only applicable to the teams involved in the league, specific to the 2019-2020 season. Second, the 1st to 4th quarter game-related statistics were analysed in this study. Inclusion of variables in shorter periods (per quarter or halves) can help determine trends in winning and losing in relation to phases of the game. Lastly, only regular-season games were included in this study. Future studies should include a comparison of the regular-season and postseason games to help establish the critical factors in higher competitive stages of the season.

This study highlighted the game-related statistics differentiating winning and losing in a men's university basketball league in the Philippines. Winning and losing games in balanced and unbalanced games are differentiated by offensive and defensive variables that are crucial for gaining an advantage against the opponents. The findings of this study can help coaches design and implement a basketball training programme that develops appropriate offensive and defensive skills essential to game success.

\section{References}

Conte, D. \& Lukonaitiene, I. (2018). Scoring strategies differentiating between Winning and losing teams during FIBA EuroBasket Women 2017. Sports, 6(2), 50. doi: $10.3390 /$ sports 6020050

Conte, D., Favero, T.G, Niederhausen, M., Capranica, L., \& Tessitore, A. (2017). Determinants of the effectiveness of fast break actions in elite and sub-elite Italian men's basketball games. Biology of Sport, 34(2), 177-183. doi: 10.5114/biolsport.2017.65337

Csátaljay, G., O'Donoghue, P.G., Hughes, M., \& Henriette, D. (2009). Performance indicators that distinguish winning and losing teams in basketball. International Journal of Performance Analysis in Sport, 9, 60-66. doi: 10.1080/24748668.2009.11868464

Drust, B. (2010). Performance analysis research: meeting the challenge. Journal of Sport Sciences, 28(9), 921-922. doi: $10.1080 / 02640411003740769$

Evangelos, T., Alexandros, K., \& Nikolaos, A. (2005). Analysis of fast breaks in basketball. International Journal of Performance Analysis in Sport, 5, 17-22. doi: $10.1080 / 24748668.2005 .11868324$

Garcia, J., Ibáñez, S.J., De Santos, R.M., Leite, N., \& Sampaio, J. (2013). Identifying basketball performance indicators in regular season and playoff games. Journal of Human Kinetics, 36, 163-170. doi: 10.2478/hukin-2013-0016

Gómez, M.A., Lorenzo, A., Barakat, R., Ortega, E., \& Palao, J.M. (2008). Differences in game-related statistics of basketball performance by game location for men's winning and losing teams. Perceptual and Motor Skills, 106(1), 43-50. doi: 10.2466/PMS.106.1.43-50

Gómez, M.Á., Pérez, J., Molik, B., Szyman, R.J., \& Sampaio, J.
(2014). Performance analysis of elite men's and women's wheelchair basketball. Journal of Sports Sciences, 32(11), 1066-75. doi: 10.1080/02640414.2013.879334

Ibáñez S.J., García J., Feu S., Lorenzo A., \& Sampaio J. (2009). Effects of consecutive basketball games on the gamerelated statistics that discriminate winner and losing teams. Journal of Sports Science \& Medicine, 8(3), 458-462.

Ibáñez S.J., Sampaio, J., Calvo, A., \& Ruano, M. (2008). Gamerelated statistics that discriminated winning and losing teams from the Spanish Men's professional basketball teams. Collegium Antropologicum, 32(2), 451-6.

Ibáñez S.J., Sampaio, J., Feu, S., Lorenzo, A., Gómez, M.A. \& Ortega, E. (2008). Basketball game-related statistics that discriminate between teams' long-season success. European Journal of Sport Sciences, 8(6), 369-372. doi: $10.1080 / 17461390802261470$

Krause J., Meyer D., Meyer J (2008). Basketball Skills and Drills (3rd ed). Champaign, IL: Human Kinetics, 214-227

Lorenzo, A., Gómez, M.Á, Ortega, E., Ibáñez, S.J, \& Sampaio, J. (2010). Game related statistics which discriminate between winning and losing under-16 male basketball games. Journal of Sports Science \& Medicine, 9(4), 664-668.

Oliver, D. (2004). Basketball on Paper: Rules and Tools for Performance Analysis. Washington: Potomac Books.

Pakosz, P. \& Konieczny, M. (2016). Time analysis of muscle activation during basketball free throws. Central European Journal of Sport Sciences and Medicine, 15, 73-79. doi: 10.18276/cej.2016.3-07

Sampaio, J., \& Janeira, M. (2003). Statistical analyses of basketball team performance: understanding teams wins and losses according to a different index of ball possessions. International Journal of Performance Analysis in Sport. 3(1), 40-49. doi: 10.1080/24748668.2003.11868273

Sampaio, J., Godoy, S.I, \& Feu, S. (2004). Discriminative power of basketball game-related statistics by level of competition and sex. Perceptual and Motor Skills, 99(3), 1231 - 1238. doi: 10.2466/pms.99.3f.1231-1238

Sampaio, J., Ibáñez, S.J, Lorenzo, A. \& Gómez, M. (2006). Discriminative game-related statistics between basketball starters and non-starters when related to team quality and game outcome. Perceptual and Motor Skills, 103(2): 486494. doi: 10.2466/pms.103.2.486-494

Sampaio, J., McGarry, T., Calleja-González, J., Sáiz, S.J., Schelling i del Alcázar X., \& Balciunas, M. (2015). Exploring game performance in the National Basketball Association using player tracking data. PLoS ONE, 10(7). doi: 10.1371/journal.pone.0132894

Trninić , S., Dizdar, D., \& Dezman, B. (2000). Empirical verification of the weighted system of criteria for the elite basketball players quality evaluation. Collegium Antropologicum, 24, 443-465.

Trninić, S., Dizdar, D., \& Lukšić, E. (2002). Differences between winning and defeated top quality basketball teams in final tournaments of European Club Championship. Collegium Antropologicum, 26(2), 521-531.

Wootten, M., \& Wootten, J. (2012). Coaching basketball successfully (3rd ed). Champaign, IL: Human Kinetics.

Ziv, G., Lidor, R., \& Arnon, M. (2010). Predicting team rankings in basketball: The questionable use of oncourt performance statistics. International Journal of Performance Analysis in Sport, 10(2), 103-114. doi: 10.1080/24748668.2010.11868506 